\title{
The relation of preventive dental behaviors to periodontal health status
}

\author{
W. Paul Lang', \\ Mahassen M. Farghaly ${ }^{1}$ and \\ David L. Ronis ${ }^{2}$ \\ ${ }^{1}$ School of Dentistry, University of Michigan, \\ Ann Arbor, Michigan 48109-1078, USA: \\ ${ }^{2}$ Institute for Social Research, University of \\ Michigan, Ann Arbor, Michigan 48106-1248, \\ and Health Services Research and \\ Development Program, Department of \\ Veterans Affairs, Ann Arbor, \\ Michigan 48113-0170, USA
}

\begin{abstract}
Lang WP, Farghaly MM, Ronis DL: The relation of preventive dental behaviors to periodontal health status. J Clin Periodontol 1994; 21: 194-198. (C) Munksgaard, 1994.
\end{abstract}

\begin{abstract}
Current recommendations for periodontal health maintenance emphasize toothbrushing, flossing and periodic dental checkups. The purposes of this study were to examine (1) the effects of these practices on periodontal health and (2) the relationships of demographic and socioeconomic variables with these behaviors and with periodontal health. Adults $(n=319)$ in the Detroit, Michigan tri-county area were asked how frequently they performed the 3 preventive behaviors. Levels of plaque, gingivitis, calculus, and periodontal attachment were then assessed during in-home dental examinations. There were no statistically significant differences in these health measures between those with acceptable and unacceptable brushing behavior. About $20 \%$ of the subjects reported acceptable flossing behavior, and these individuals had significantly less plaque and calculus than other participants. Over $3 / 4$ of subjects reported having a dental checkup at least $1 \times$ a year, and these persons were found to have significantly less plaque, gingivitis, and calculus compared to less frequent attenders. Acceptable brushing behavior was not associated with any particular demographic or socioeconomic characteristic, while differences in acceptable flossing behavior were found among age groups. Frequencies of yearly dental checkups varied significantly within every demographic and socioeconomic characteristic.
\end{abstract}

Key words: toothbrushing; flossing; dental checkups; preventive behaviors; dental health.

Accepted for publication 20 April 1993
Currently, toothbrushing, flossing, and periodic dental visits are the fundamental elements for preventing periodontal disease (Frandsen 1985). Recommendations regarding frequency of these behaviors suggest that brushing and flossing be performed thoroughly at least $1 \times$ a day, while dental visits should be made on a regular basis (American Dental Association 1988).

The frequency of these behaviors and their effects on oral health have been periodically examined. For example, toothbrushing is a nearly universal behavior, and has been reported consistently in similar pattern for nearly 30 years with few variations among demographic groups (Gift 1985, Ronis et al. 1992). The effectiveness of toothbrushing for removing plaque and controlling gingivitis has been established (Walsh et al. 1989). However, there is little evidence that links brushing frequency with improved oral health, particularly in natural, uncontrolled settings (Gift 1985).

Flossing is practiced by fewer individuals but frequency has slowly increased over the years with women and the educated being more frequent flossers (Ronis et al. 1992). Flossing has been shown to reduce gingival inflammation (Graves et al. 1989), but the added benefits of toothbrushing and flossing over toothbrushing alone are uncertain (Frandsen 1985).

Demographic factors such as age, gender, and race, and socioeconomic status are known to affect the frequency of dental visits (Burt \& Eklund 1992). Of 3 preventive behaviors (regular dental visits, consistent tooth brushing, tooth brushing time) studied by Melsen et al. (1987), only dental visits was found to be a strong predictor of dental health status. Ultrafrequent visits (every 2 weeks) have been shown to be successful in helping maintain oral hygiene and subsequent periodontal health in periodontal patients (Nyman et al. 1975), but such frequent attendance is not practical as a routine preventive regimen.

In summary, maintenance of periodontal health is presumed to depend on some combination of toothbrushing, flossing and periodic dental visits. Further, the extent to which these behaviors are performed will vary by an individual's demographic and socioeconomic status. Given the uncertain relation of the 3 preventive behaviors with periodontal health and the vari- 
ability of performance among different groups, this study was undertaken to examine (1) the effects of these practices on periodontal health and (2) the relationships of demographic and socioeconomic variables with these behaviors and with periodontal health.

\section{Material and Methods}

The subjects for this study were individuals who consented to a dental examination as part of a 2-phase research project on brushing, flossing, and obtaining dental checkups. Phase-I involved hourlong face-to-face interviews on a probability sample of adults 18 years of age or older, having at least 1 tooth, and living in housing units in the Detroit tricounty area. The response rate for the interviews was $72 \%$; 662 interviews were conducted. The details of phase-I are reported elsewhere (Ronis et al. 1992). At the time of the interview, subjects were solicited to participate in phase-II that consisted of a $40-\mathrm{min}$ in-home dental examination, observation of personal oral hygiene activities, and a 2 nd brief interview. The response rate for phase-II was $60 \%(N=397)$ of those who participated in phase-I. A variety of health conditions prevented completion of examinations on some subjects; 319 subjects completed all portions of the in-home examination visit. Informed consent was obtained from all participants.

Brushing, flossing, and dental checkup frequencies were acquired in phaseI by asking subjects how often they performed these activities. Brushing and flossing variables were refined by including measures of thoroughness. To be considered as having acceptable brushing behavior, a subject had to (1) brush at least once daily during the past year, (2) brush all his/her teeth, and (3) usually brush parts of the teeth that don't show when they smiled. A subject who did not report performing all 3 aspects of brushing was considered to have unacceptable brushing behavior. For acceptable flossing behavior, a subject had to (1) floss at least once daily during the past year, and (2) usually floss all of his/her teeth. A subject who did not report performing these 2 aspects of flossing was considered to have unacceptable flossing behavior.

Check-ups were defined for subjects, as "...visits to a dental office or clinic made not because of any dental problem." Subjects were then asked whether they had ever had a check-up, and how often they had gone to a dentist or dental clinic for a check-up during the past five years. Responses were dichotomized as subjects had (1) check-ups at least once a year or (2) check-ups $<1 \times$ a year or never.

Plaque, gingivitis, calculus, pocket depths, and loss of periodontal attachment (LPA) were measured on the six teeth specified by Ramfjord (1959). Plaque and gingivitis were assessed using the plaque and gingival indices (Löe \& Silness 1963, Silness \& Löe 1964), while calculus was measured according to scoring criteria and methods of Ramfjord (1967). Pocket depth and LPA were measured using a $\mathrm{Hu}$-Friedy number 11 probe. Pocket depth was measured in millimeters from the free gingival margin to the base of a pocket. The distance from cementoenamel junction (CEJ) to the base of the pocket was also measured. The difference between these measurements was considered to be loss of periodontal attachment (LPA). 5 examiners were trained and calibrated in the several indices using written and visual criteria. Inter-examiner $\%$ agreement on attachment loss (within $\pm 1 \mathrm{~mm}$ ) ranged from $87 \%$ to $94 \%$; $x$ 's ranged from 0.37 to 0.62 . Intra-examiner $\%$ agreement ranged from $94 \%$ to $97 \%$; $\%$ 's were 0.66 to 0.84 . \%'s were within ranges observed in a recent US national survey (Brown et al. 1990).

Distributions of subjects by demographic and socioeconomic categories were developed for analysis by recording age, income, and education level into 4 categories. Age was categorized as 18 to 29 years, 30 to 39 years, 40 to 54 years, and 55 years or older. Income was categorized as <U.S. $\$ 20,000$, $\$ 20-34,999, \$ 35-50,999$ and $\geqslant \$ 51,000$. Education level was derived by stratifying the years of education into the following categories: $\leqslant 11$ years, 12 years, 13 to 14 years, and $\geqslant 15$ years. For race, a non-white category was developed for analysis that included all minorities. Almost all $(91 \%)$ of non-white subjects were African American. Mean values for variables of interest were generated and compared using analysis of variance (ANOVA).

\section{Results}

Table 1 displays demographic and socioeconomic characteristics of the sample and mean values and standard deviations for measures of periodontal health status. The mean age of the total sample was $43.6(\mathrm{SD}=15.9)$ years. The youngest age group, 18 to 29 years, comprised $20 \%$ of the sample while $1 / 4$ of subjects was age 55 years or older. More plaque and calculus were found in the oldest subjects, and these differences were statistically significant. Mean pocket depth was less for the youngest age group. As expected, loss of periodontal attachment increased with age. The youngest age group had lost only $0.42 \mathrm{~mm}$ of attachment while the oldest group had a mean attachment loss of $2.3 \mathrm{~mm}$. Differences among groups for attachment loss were statistically significant.

Females comprised about $56 \%$ of the sample. The mean values for all measures of periodontal health status were lower (more favorable) for females than for males. However, only differences in pocket depth and loss of attachment were statistically significant. $17 \%$ of the sample was non-white, and these individuals exhibited about $1.5 \times$ as much plaque and gingivitis as whites and about $2.5 \times$ as much calculus. These differences were statistically significant. Mean pocket depths and attachment loss were also significantly different between the two groups.

About $19 \%$ of the sample reported incomes of less than $\$ 20,000$ while a third of subjects reported incomes of $\$ 51,000$ or more. The mean number of years of education for the total sample was $13.4(\mathrm{SD}=2.4)$. About $10 \%$ of subjects had completed less than 12 years of education while nearly $1 / 3$ had completed more than 14 years of education. Differences in periodontal status were related to the socioeconomic factors. As socioeconomic status improved, the presence of plaque, calculus, and gingivitis generally declined. Differences in plaque, calculus, and gingivitis among groups were statistically significant. Calculus, for example, was $2-3 \times$ more prevalent in the lowest income and education groups compared to the highest level groups in those categories. Pocket depths were deeper and there was $2 \times$ as much attachment loss in the lowest education group compared to the highest education group. Generally, all measures of periodontal status demonstrated inverse relations with income and education levels. $70 \%$ of subjects reported having dental insurance, but oral health status was not found to be appreciably different between those with or without insurance.

Table 2 displays the $\%$ of examined 
Table 1. Means and standard deviations for measures of periodontal health status by demographic and socioeconomic characteristics

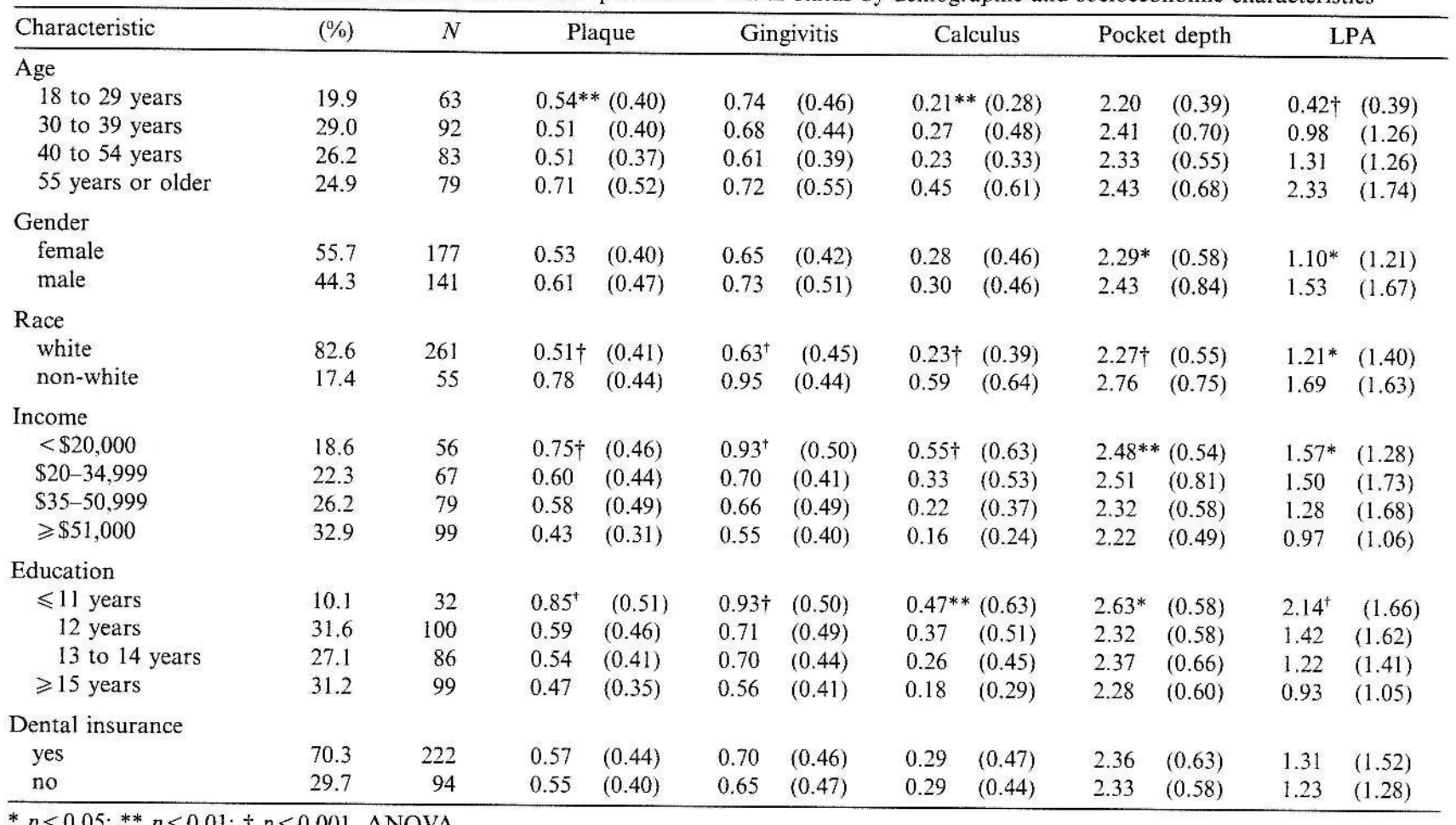

$* p<0.05 ;{ }^{* *} p<0.01 ; \dagger p<0.001$, ANOVA.

subjects that reported performing the three preventive behaviors, and the relation of these behaviors to the measures of periodontal health. Acceptable brushing behavior was reported by $84 \%$ of the subjects. There were no significant differences in health measures between those with acceptable and unacceptable brushing behavior. However, there was a trend of smaller values in the group with acceptable behavior. Only $21 \%$ of the subjects reported having acceptable flossing behavior. Overall, persons reporting acceptable flossing behavior had significantly less plaque and calculus than the remainder of the sample. Over $3 / 4$ of those examined reported having a den- tal checkup at least once a year, and these individuals had significantly less plaque, calculus, and gingivitis than those who reported less frequent visits. Further, individuals that reported having a dental checkup at least once a year had significantly lower pocket depths and less attachment loss.

Table 3 displays the percentage of subjects performing the preventive behaviors by demographic and socioeconomic characteristics. No particular characteristic was associated with acceptable brushing behavior. The only demographic characteristic that displayed a statistically significant relationship with flossing was age. Subjects age 30 to 39 years old were most likely to report acceptable flossing behavior followed by subjects in the oldest age group. The youngest age group was least likely to report acceptable flossing behavior. Yearly checkups demonstrated a statistically significant relation with every demographic and socioeconomic characteristic. The individuals most likely to report a yearly check-up were subjects in the 2 middle age groups, females, whites, those with higher incomes and more education, and those covered by dental insurance. Generally, preventive behaviors and periodontal health varied similarly across demographic groups, that is, subgroups performing more preventive behaviors had better periodontal health.

Table 2. Means and standard deviations for measures of periodontal health status by reported preventive behaviors

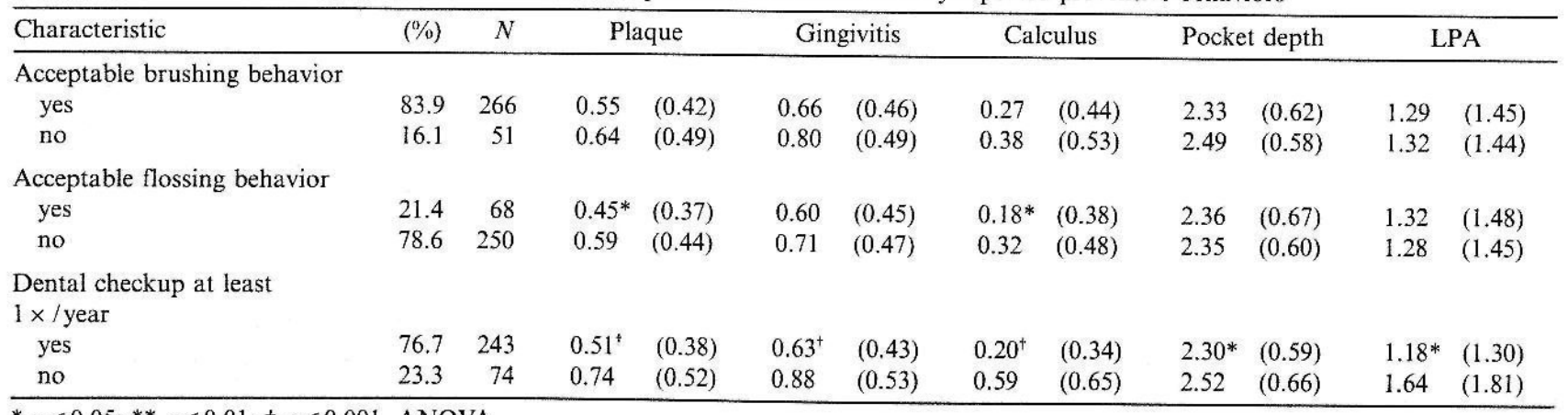

$* p<0.05 ; * *<<0.01 ; \dagger p<0.001$, ANOVA. 
Table 3. Demographic and socioeconomic characteristics in relation to reported preventive behaviors

\begin{tabular}{|c|c|c|c|c|}
\hline Characteristic & $N$ & $\begin{array}{l}\% \text { with } \\
\text { acceptable } \\
\text { brushing }\end{array}$ & $\begin{array}{l}\% \text { with } \\
\text { acceptable } \\
\text { flossing }\end{array}$ & $\begin{array}{c}\% \text { with } \\
\text { yearly dental } \\
\text { check-up }\end{array}$ \\
\hline \multicolumn{5}{|l|}{ Age } \\
\hline 18 to 29 years & 63 & 79.4 & $9.5 *$ & $65.1^{*}$ \\
\hline 30 to 39 years & 92 & 80.4 & 29.3 & 77.2 \\
\hline 40 to 54 years & 82 & 85.4 & 20.7 & 85.5 \\
\hline 55 years or older & 80 & 90.0 & 23.8 & 75.9 \\
\hline \multicolumn{5}{|l|}{ Gender } \\
\hline female & 177 & 87.6 & 23.7 & $81.4^{*}$ \\
\hline male & 141 & 79.4 & 19.1 & 70.2 \\
\hline \multicolumn{5}{|l|}{ Race } \\
\hline white & 261 & 85.1 & 22.2 & $80.8^{* * *}$ \\
\hline non-white & 55 & 78.2 & 20.0 & 56.4 \\
\hline \multicolumn{5}{|l|}{ Income } \\
\hline$<\$ 20,000$ & 56 & 80.4 & 12.5 & $55.4^{* * *}$ \\
\hline$\$ 20-34,999$ & 68 & 77.9 & 19.1 & 67.6 \\
\hline$\$ 35-50,999$ & 79 & 83.5 & 29.1 & 89.9 \\
\hline$\geqslant \$ 51,000$ & 98 & 88.8 & 25.5 & 87.8 \\
\hline \multicolumn{5}{|l|}{ Education } \\
\hline$\leqslant 11$ years & 32 & 78.1 & 6.3 & $46.9^{* * *}$ \\
\hline 12 years & 101 & 84.2 & 19.8 & 70.0 \\
\hline 13 to 14 years & 86 & 82.6 & 26.7 & 84.9 \\
\hline$\geqslant 15$ years & 98 & 86.7 & 24.5 & 84.8 \\
\hline \multicolumn{5}{|l|}{ Dental insurance } \\
\hline yes & 222 & 84.2 & 24.7 & $81.5^{* * *}$ \\
\hline no & 94 & 83.0 & 14.9 & 63.8 \\
\hline
\end{tabular}

${ }^{*} p<0.05 ; * * p<0.01 ; * * * p<0.001, \varkappa^{2}$ test.

\section{Discussion}

The decline in periodontal health status observed with increasing subject age demonstrates the accumulation of disease effects over the life span. Our finding of slightly better periodontal health in females is probably related to the better oral hygiene practices consistently demonstrated by females (Gift 1985). The periodontal health differences observed between racial groups is likely due to socioeconomic variables (Ronis et al. 1992), rather than to differences in disease prevalence attributable to race or ethnicity per se. Several of our findings: inverse relations between periodontal health and education and income levels, and lack of association between possession of dental insurance and better periodontal health, concur with findings from national surveys (Oliver et al. 1991).

All measures of periodontal health status were positively related to acceptable brushing behavior, but none demonstrated a statistically significant relation. Differences in amounts of plaque and calculus (potential initiators of periodontal diseases) were observed between subjects with acceptable and un- reliably associated with acceptable brushing behavior, but this may be expected given that tooth brushing is an almost ubiquitous behavior. For flossing, age was the only demographic characteristic that varied among subjects with acceptable or unacceptable behavior. It was somewhat surprising to observe that our oldest subjects were next most likely to floss after the 30 to 39 year-old group. This finding is encouraging, but could also be due to members of this group responding in a normative fashion. However, because so few subjects in any age group were flossing adequately, education should still be directed at all patients. The strong statistical relation of yearly checkups with the demographic and socioeconomic characteristics demonstrates that such issues as gender, race, income, and education level still affect access to care. In part, dental professionals can address limited access either personally or through appropriate media by educating groups about the value of regular preventive visits. Unfortunately, financial barriers are more difficult to overcome.

In summary, acceptable flossing behavior and regular dental checkups were found to be positively associated with some aspects of better periodontal health. Demographic status and socioeconomic status were most likely to affect dental attendance. The dental profession should continue to recommend current preventive behaviors adapted to the status of their patients.

\section{Acknowledgments}

This research was supported by NIDR Grant DE07800 to DLR. The authors thank Kim Krueger for her assistance with data management and analysis.

\section{Zusammenfassung}

Die Beziehung zwischen vorbeugenden Zahnpflegegewohnheiten und dem parodontalen $\mathrm{Ge}$ sundheitszustand

Aktuelle Empfehlungen für die Beibehaltung der parodontalen Gesundheit unterstreichen die Bedeutung der mechanischen Reinigung mit Zahnbürsten, der Anwendung von Zahnseide und von regelmäßigen zahnärztlichen Untersuchungen. Mit dieser Studie wird beabsichtigt (1) die Auswirkungen der oben genannten Verfahrensweisen auf die parodontale Gesundheit und (2) die Beziehungen demographischer und sozioökonomischer Variablen zu diesen gewohnheitsmäßig vorgenommenen Handlungen und zu der parodon- 
talen Gesundheit zu untersuchen. In dem Detroit, Michigan Dreistaateneck wohnende Erwachsene $(N=319)$ wurden nach der Häufigkeit der Anwendung dieser 3 vorbeugenden Methoden befragt. Bei häuslich vorgenommenen, zahnärztlichen Untersuchungen wurde das Vorkommen von Plaque, Gingivitis, Zahnstein und die periodontale Attachmentebene beurteilt. Bei diesen Bestimmungen der Zahngesundheit wurden zwischen Probanden mit akzeptabler und nicht akzeptabler mechanischer Reinigung mit Zahnbürsten keine statistich abgesicherten Unterschiede festgestellt. Etwa $20 \%$ der Probanden gaben aus zahnärztlicher Sicht annehmbare Reinigungsgewohnheiten mit der Zahnseide an und bei ihnen wurde signifikant weniger Plaque und Zahnstein gesehen als bei anderen Versuchsteilnehmern. Mehr als 3/4 der Probanden gaben an, zumindest einmal jährlich zahnärtzlich untersucht $\mathrm{zu}$ werden. Im Vergleich zu weniger häufig untersuchten Versuchsteilnehmern wurde bei diesen Probanden deutlich weniger Plaque, Gingivitis und Zahnstein konstatiert. Zahnärztlich akzeptable, gewohnheitsmäßige Reinigung mit Zahnbürsten ging nicht mit demographischen oder sozioökonomischen Besonderheiten einher, wohingegen zwischen den Altersgruppen Unterschiede hinsichtlich zahnärztlich akzeptabler Reinigungsgewohnheiten mit der Zahnseide vorlagen. Die Vorkommenshäufigkeiten jährlicher zahnärztlicher Untersuchungen variierten signifikant mit jedem demographischen und sozioökonomischen Charakteristikum.

\section{Résumé}

Comportements dentaires préventifs et état de santé du parodonte

Les recommendations actuelles pour le maintien de la santé parodontale comprennent souvent le brossage dentaire, l'utilisation du fil et les visites dentaires périodiques. Le double but de cette étude a été d'examiner (1) l'effet de ces comportements sur la santé parodontale et (2) la relation des variables démographiques et socioéconomiques avec ces comportements et avec la santé parodontale. 319 adultes de Détroit (Michigan, USA) ont expliqué comment ils suivaient ces recommandations. Les niveaux de plaque, de gingivite, de tartre et de niveau d'attache ont ensuite été mesurés à domicile. Il n'y avait aucune différence significative dans ces mesures entre ceux avec ou sans comportement acceptable de brossage. Environ 20\% des sujets disaient utiliser le fil dentaire et ces derniers avaient significativement moins de plaque et de tartre que les autres participants. Plus des $3 / 4$ des individus passaient au moins une visite dentaire annuelle et ces derniers avaient significativement moins de plaque, de gingivite et de tartre que les autres. Un comportement adéquat de brossage n'était associé à aucune caractéristique démographique ou socioéconomique particulière tandis que des différences dans le comportement acceptable vis-à-vis du fil dentaire étaient visibles parmi les groupes d'âge. Les fréquences de visites dentaires annuelles variaient à l'intérieur de chaque groupe démographique et socioéconomique.

\section{References}

American Dental Association (1988) Wake up to prevention for the smile of a lifetime. Journal of the American Dental Association 116, 3G, 6G-13G

Brown, L. J., Oliver, R. C. \& Löe, H. (1990) Evaluating periodontal status of US employed adults. Journal of the American Dental Association 121, 226-232.

Burt, B. \& Eklund, S. (1992). Dentistry; dental practice and the community, 4th edition, $339 \mathrm{pp}$. Philadelphia, W. B. Saunders.

Frandsen, A. (1985) Mechanical oral hygiene practices. State-of-the-science review. Dental plaque control measures and oral hygiene practices. Bethesda, MD: IRL Press.

Gift, H. C. (1985) Current utilization patterns of oral hygiene practices. State-of-thescience review. Dental plaque control measures and oral hygiene practices. Bethesda, MD: IRL Press.

Glavind, L. \& Nyvad, B. (1986) The scientific basis for oral health recommendations for self care. Promotion of self care in oral health. Oslo, Norway: Scandinavian Working Group for Preventive Dentistry. Graves, R. C., Disney, J. A. \& Stamm, J. W. (1989) Comparative effectiveness of flossing and brushing in reducing interproxi- mal bleeding. Journal of Periodontology $\mathbf{6 0}$, 243-247.

Löe, H. \& Silness, J. (1963) Periodontal disease in pregnancy, I. Prevalence and severity. Acta Odontologica Scandinavica 21, 533-551.

McFall, W. J., Bader, J. D., Rozier, R. G., Ramsey, D., Graves, R., Sams, D. \& Sloame, B. (1989) Clinical periodontal status of regularly attending patients in general dental practices. Journal of Periodontology 60, 145-150.

Melsen, B., Hørup, N. \& Terp, S. (1987) Factors of importance for maintenance of teeth. Community Dental Health 4, 11-25.

Nyman, S., Rosling, B. \& Linde, J. (1975) Effect of professional toothcleaning on healing after periodontal surgery. Journal of Clinical Periodontology 2, 80-86.

Oliver, R. C., Brown, L. J. \& Löe, H. (1991) Variations in the prevalence and extent of periodontitis. Journal of the American Dental Association 122, 43-48.

Ramfjord, S. P. (1959) Indices for prevalence and incidence of periodontal disease. Journal of Periodontology 30, 51-59.

Ramfjord, S. P. (1967) The periodontal disease index (PDI). Journal of Periodontology 38, suppl., 602-610.

Ronis, D. L., Lang, W. P., Farghaly, M. M. \& Passow, E. (1993) Tooth brushing, flossing and preventive dental visits by Detroitarea residents in relationship to demographic and socioeconomic factors. Journal of Public Health Dentistry 53, 138-145.

Silness, J. \& Löe, H. (1964) Periodontal disease in pregnancy. II. Correlation between oral hygiene and periodontal disease. Acta Odontologica Scandinavica 22, 121-135.

Walsh, M., Heckman, B., Leggott, P., Armitage, G. \& Robertson, P. B. (1989) Comparison of manual and power toothbrushing, with and without adjunctive oral irrigation, for controlling plaque and gingivitis. Journal of Clinical Periodontology 16, 419-427.

Address:

W. P. Lang

Department of Periodontics/Prevention/ Geriatrics

University of Michigan School of Dentistry

1011 North University

Ann Arbor, Michigan 48109-1078

USA 
This document is a scanned copy of a printed document. No warranty is given about the accuracy of the copy. Users should refer to the original published version of the material. 